\title{
Adenosine induces intrinsic apoptosis via the PI3K/Akt/mTOR signaling pathway in human pharyngeal squamous carcinoma FaDu cells
}

\author{
MI SUK CHOI ${ }^{1 *}$, SUNG-MIN MOON ${ }^{2 *}$, SEUL AH LEE ${ }^{3}$, BO-RAM PARK $^{1}$, JAE-SUNG KIM $^{4}$, \\ DO KYUNG KIM ${ }^{5}$, YONG HWAN KIM ${ }^{6}$ and CHUN SUNG KIM ${ }^{3}$
}

\author{
${ }^{1}$ Department of Dental Hygiene, Chodang University, Muan-ro, Muan-eup, Muan 534-701; ${ }^{2}$ CStech Research Institute, \\ Gwangju, South Jeolla 61007; ${ }^{3}$ Department of Oral Biochemistry, College of Dentistry; ${ }^{4}$ Pre-Dentistry, College of Dentistry; \\ ${ }^{5}$ Department of Oral Physiology, College of Dentistry, Chosun University, Gwangju, South Jeolla 501-759; \\ ${ }^{6}$ Department of Crop Science and Biotechnology, College of Life and Resource Science, \\ Cheonan, Chungnam 31116, Republic of Korea
}

Received April 7, 2017; Accepted October 13, 2017

DOI: $10.3892 / \mathrm{ol} .2018 .8089$

\begin{abstract}
Adenosine has been identified to occur abundantly intra-and extracellularly, and to exert diverse biological functions, including the suppression of cell proliferation and the induction of apoptosis. Adenosine has been reported to induce apoptosis in several cancer cell lines; however, to the best of our knowledge, the effect of adenosine on head and neck cancer cells has not been investigated. Therefore, the purpose of the present study was to evaluate whether adenosine exerts any anticancer effect via induction of apoptosis in human pharyngeal squamous carcinoma FaDu cells. An MTT assay demonstrated that adenosine-treated $\mathrm{FaDu}$ cells inhibited a dose-dependent rate of cell growth, whereas human oral keratinocytes cells were unaffected by adenosine treatment. In addition, $A_{1}$ and $A_{2 a}$ adenosine receptor mRNA was detected in $\mathrm{FaDu}$ cells by reverse transcription-polymerase chain reaction, and adenosine-induced FaDu cell death was significantly suppressed by treatment with ATL-444, an antagonist of these receptors. Furthermore, adenosine-induced cell growth inhibition was exerted via apoptosis, as confirmed by the analysis of DNA fragmentation, Hoechst nuclear staining and flow cytometry with Annexin V-fluorescein isothiocyanate and propidium iodide staining. Adenosine was also demonstrated to induce an increase in Bcl-associated $\mathrm{X}$
\end{abstract}

Correspondence to: Professor Chun Sung Kim, Department of Oral Biochemistry, College of Dentistry, Chosun University, 375 Seosuk-dong, Dong, Gwangju, South Jeolla 501-759, Republic of Korea

E-mail: cskim2@chosun.ac.kr

*Contributed equally

Key words: adenosine, $\mathrm{FaDu}$ human pharyngeal squamous carcinoma cells, mitochondrial intrinsic apoptotic pathway, PI3K, Akt, mTOR expression, a decrease in B-cell lymphoma 2 expression, the release of cytochrome $c$ from mitochondria, and the activation of caspase-3, -9 and poly(ADP-ribose) polymerase in FaDu cells. Finally, phosphoinositide 3-kinase (PI3K), RAC serine/threonine-protein kinase (Akt) and mechanistic target of rapamycin (mTOR) phosphorylation was found to be significantly inhibited in adenosine-treated $\mathrm{FaDu}$ cells, as was phosphorylation of the mTOR downregulators, S6 kinase $\beta 1$, eukaryotic translation initiation factor 4E-binding protein 1 , and eukaryotic translation initiation factor $4 \gamma 1$. Taken together, these results indicate that adenosine induces apoptosis via the mitochondrial intrinsic pathway, and activates caspase-3 and -9 activity via the PI3K/Akt/mTOR signaling pathway.

\section{Introduction}

Head and neck squamous cell carcinomas (HNSCC) represent $4 \%$ of all cancer cases worldwide (1). They primary source ( $41 \%$ of cases) is the oral cavity, but they are also often found in the pharynx and larynx, (22 and 24\% of cases, respectively) (2). The majority of patients with HNSCC are clinically identified prior to metastasis, and therefore are potentially able to be cured by an aggressive therapy regimen, comprising surgery, chemotherapy and/or radiotherapy (3). Nevertheless, despite recent improvements to utilized surgical techniques, chemotherapy and radiation delivery, and supportive care, which have improved the quality of life of patients, the HNSCC disease recurrence rate remains unacceptably high, occurring in up to $50 \%$ of patients within the first 2 years of diagnosis $(4,5)$. Thus, there is an urgent requirement for the development of novel drugs that can be safely integrated into current treatment regimens to improve the tolerability and the efficacy of current treatments. Currently, patients with HNSCC are treated with several anticancer drugs, including paclitaxel, 5-fluorouracil (5-FU), cisplatin, and docetaxel.

Adenosine is a purine nucleoside that is composed of an adenine molecule covalently attached to a ribose sugar molecule, and is found in abundance intra- and extracellularly (6). 
Adenosine is known to induce growth suppression and apoptosis in multiple types of cancer cells via at least two independent pathways. For example, adenosine induces apoptosis by activating specific extracellular $\mathrm{A}_{1}, \mathrm{~A}_{2 \mathrm{a}}, \mathrm{A}_{2 \mathrm{~b}}$, and $\mathrm{A}_{3}$ receptors in a number of types of cancer, including gastric cancer (7), breast cancer (8), colon cancer (9), leukemia (10) and melanoma (11). Similarly, the intracellular transportation of adenosine induces the inhibition of cell growth and apoptosis via non-receptor-mediated pathways. The apoptotic effects induced by numerous anticancer drugs occur via diverse signaling pathways, and are regulated by complex mitochondrial-extrinsic and -intrinsic pathways. Two crucial apoptotic pathways are distinguished according to the presence or absence of caspase involvement. The first of these is the mitochondrial-intrinsic pathway, in which activation of B-cell lymphoma-2 (Bcl-2)-family proteins leads to mitochondrial permeabilization and the release of cytochrome $c$ from the mitochondria to the cytoplasm, and thus to the activation of the initiator (caspase-9) and downstream effector (caspase-3) caspases (12). Activated caspase-3 then cleaves various substrates, including cytokeratins, poly(ADP-ribose) polymerase (PARP), and nuclear mitotic apparatus protein, ultimately mediating the morphological and biochemical changes that are characteristic of apoptotic cells (13). Alternatively, Bcl-2 activation is regulated by the post-translational phosphorylation of phosphoinositide-3 kinase $(\mathrm{PI} 3 \mathrm{~K}) / \mathrm{RAC}$ serine/threonine-protein kinase $(\mathrm{Akt})$ signaling $(14,15)$. In fact, PI3K/Akt signaling is frequently dysregulated and/or constitutively activated in multiple cancer types, including breast, bladder, prostate, thyroid, ovarian and non-small cell lung cancer $(16,17)$. Akt is capable of phosphorylating substrates involved in a number of processes, including cell proliferation (p27, cyclin D1), survival (Bcl-2 family, caspases), and growth [mechanistic target of rapamycin (mTOR)]; thus, drugs that target Akt either directly, or via elements of the Akt pathway, are promising targets for cancer therapy (18).

In the present study, the FaDu human pharyngeal squamous carcinoma cell line was used to investigate whether adenosine induced cell death via the adenosine receptors, and to establish the mechanism underlying this process, in the context of HNSCC.

\section{Materials and methods}

Materials. Adenosine and ATL-444 (a selective antagonist for the $A_{1}$ and $A_{2 a}$ adenosine receptors) were purchased from Sigma-Aldrich; Merck KGaA (Darmstadt, Germany). The primary antibodies anti-PI3K, anti-phospho PI3K, anti-Akt, anti-phospho Akt (ser473), anti-mTOR, anti-phospho mTOR (ser2448), anti-phospho S6 kinase $\beta 1$ (S6K1), anti-phospho eukaryotic translation initiation factor 4E-binding protein 1 (4EBP1), anti-phospho eukaryotic translation initiation factor $4 \gamma 1$ (eIF4G), anti-caspase-9, anti-caspase-3, anti-PARP, anti-Bcl-associated X (Bax), anti-Bcl-2, and anti-cytochrome $c$ were purchased from Cell Signaling Technology, Inc. (Danvers, MA, USA). The primary antibodies anti-adenosine $A_{1}$ receptor, anti-adenosine $A_{2 a}$ receptor, anti-adenosine $A_{2 b}$ receptor, anti-adenosine $A_{3}$ receptor were purchased from Abcam (Cambridge, MA, USA). The primary anti- $\beta$-actin (cat. no. sc-47778) antibody was purchased from Santa Cruz Biotechnology, Inc. (Dallas, TX, USA).

Cell culture. Normal human oral keratinocytes (NHOKs) were purchased from ScienCell Research Laboratories, Inc. (San Diego, CA, USA). NHOKs were maintained in Keratinocyte Growth Medium supplemented using a supplementary growth factor bullet kit (Clonetics Corp., San Diego, CA, USA). The FaDu human pharynx squamous carcinoma cell line was maintained in Dulbecco's modified Eagle's medium supplemented with $10 \%$ heat-inactivated fetal bovine serum, $100 \mathrm{U} / \mathrm{ml}$ penicillin, and $100 \mu \mathrm{g} / \mathrm{ml}$ streptomycin (all from Gibco; Thermo Fisher Scientific, Inc., Waltham, MA, USA), at $37^{\circ} \mathrm{C}$ in a humidified atmosphere with $5 \% \mathrm{CO}_{2}$.

MTT assay. NHOKs and FaDu cells were seeded $\left(5 \times 10^{5}\right.$ cells/well) in 12-well plates and maintained in DMEM at $37^{\circ} \mathrm{C}$ with $5 \% \mathrm{CO}_{2}$. Once cells reached $60-80 \%$ confluency, they were treated with adenosine $(0,1.5$, or $3 \mathrm{mM})$, and co-treated with adenosine $(3 \mathrm{mM})$ and/or ATL-444 $(50 \mu \mathrm{M})$. After the indicated times, $20 \mu \mathrm{l}$ of MTT $(5 \mathrm{mg} / \mathrm{ml}$ in PBS) was added to each well, and the cells were incubated for another $4 \mathrm{~h}$ at $37^{\circ} \mathrm{C}$. The supernatants were then carefully aspirated, and $100 \mu \mathrm{l}$ of dimethyl sulfoxide was added to each well. The plates were shaken for an additional $15 \mathrm{~min}$, and then absorbance values were detected using a microplate reader at $592 \mathrm{~nm}$.

RNA isolation and reverse transcription-polymerase chain reaction $(R T-P C R)$ analysis. Total RNA was isolated from cells using TRIzol reagent (Invitrogen; Thermo Fisher Scientific, Inc.) according to the manufacturer's protocol, and reverse-transcribed using the Reverse Transcription system (Promega Corporation, Madison, WI, USA). Specifically, the sequential heating steps necessary for reverse transcription comprised $10 \mathrm{~min}$ at $25^{\circ} \mathrm{C}, 60 \mathrm{~min}$ at $42^{\circ} \mathrm{C}$, and $5 \mathrm{~min}$ at $95^{\circ} \mathrm{C}$. GAPDH was used as an internal control. The following primers were used for RT-PCR: $\mathrm{A}_{1}$ receptor forward, 5'-ACCTAATCC GCAAGCAGCTCAA-3' and reverse, 5'-ATCCTCGTCAAT GGGAGGTGCA-3'; A $_{2 \mathrm{a}}$ receptor forward, 5'-TCCCATGCT AGGTTGGAACAACTG-3' and reverse, 5'-TGATGGCCA GTGACTTGGCAGC-3'; A $_{2 b}$ receptor forward, 5'-AGTCGA CAGATACCTGGCCATCTG-3' and reverse, 5'-CATGGC CAGTGACTTGGCTGCA-3'; A $_{3}$ receptor forward, 5'-TCA TCTGCGTGGTCAAGCTGAACC-3' and reverse, 5'-CAT GTAGTCCATTCTCATGACGGA-3';. GAPDH forward, 5'-GGACTGTGGTCATGAGCCCTTCCA-3' and reverse, 5'-ACTCACGGCAAATTCAACGGCAC-3'. PCR products were visualized by gel electrophoresis with a $1.5 \%$ agarose gel.

DNA fragmentation assay. Cells were washed twice with PBS, and pelleted via centrifugation $(400 \mathrm{x} \mathrm{g}, 3 \mathrm{~min})$ at $4^{\circ} \mathrm{C}$. Cell pellets were lysed by incubation (30 min, on ice) in lysis buffer (10 $\mu \mathrm{M}$ Tris-Cl, $\mathrm{pH} 7.5,10 \mu \mathrm{M}$ EDTA, and 0.5\% Triton $\mathrm{X}-100)$. Cells were incubated for $1 \mathrm{~h}$ at $37^{\circ} \mathrm{C}$ with RNase A (sufficient volume to achieve a final concentration of $0.5 \mu \mathrm{g} / \mathrm{ml}$ in the solution), and then for $8 \mathrm{~h}$ at $50^{\circ} \mathrm{C}$ with proteinase $\mathrm{K}$ (sufficient volume to achieve a final concentration of $0.2 \mu \mathrm{g} / \mathrm{ml}$ in the solution). DNA was extracted using phenol: Chloroform:isoamyl alcohol (25:24:1), precipitated via incubation (for $24 \mathrm{~h}$, 
$\left.-70^{\circ} \mathrm{C}\right)$ with an equal volume of isopropanol, and centrifuged $\left(15,000 \times \mathrm{g}, 15 \mathrm{~min}, 4^{\circ} \mathrm{C}\right)$. The precipitated DNA was the air-dried, resuspended in $30 \mu \mathrm{l}$ of TE buffer $[10 \mathrm{mM}$ Tris- $\mathrm{HCl}$ (pH 8.0), 0.1 mM EDTA] and quantified according to its absorbance at $260 \mathrm{~nm}$ in a UV spectrophotometer. A total of $10 \mu \mathrm{g}$ DNA was separated on a $1.5 \%$ agarose gel (with added ethidium bromide) by electrophoresis at $50 \mathrm{~V}$ for $50 \mathrm{~min}$. DNA fragments were visualized using a UV trans-illuminator.

Assay for nuclear apoptosis (Hoechst staining). To determine DNA chromatin morphological features, the cells were treated with Hoechst 33342 stain, as described by Díaz-Ruiz et al (19). Subsequent to washing twice in PBS, the cells were fixed with formaldehyde (4\%, ice-cold), re-washed with PBS and Hoechst $33342(2 \mu \mathrm{g} / \mathrm{ml})$ and incubated for $30 \mathrm{~min}$ at $37^{\circ} \mathrm{C}$. Subsequent to re-washing with $\mathrm{PBS}$, cell nuclei were observed in five random fields using a fluorescence microscope (Olympus Corporation, Tokyo, Japan, magnification, x100).

Flow cytometric analysis with Annexin V-fluorescein isothiocyanate (FITC) and propidium iodine (PI) staining. The rate of apoptosis was evaluated using a Vybrant apoptosis assay kit (Molecular Probes; Thermo Fisher Scientific, Inc.) in accordance with the manufacturer's protocol. Briefly, the cells were plated $\left(2-4 \times 10^{5}\right.$ cells/dish) in six-well plates, incubated overnight, and treated for $24 \mathrm{~h}$ with adenosine $(0$ and $3 \mathrm{mM})$. They were then harvested, washed in PBS, and combined with a binding buffer containing Alexa Fluor 488 Annexin V-FITC and PI. Following incubation for $15 \mathrm{~min}$ at $37^{\circ} \mathrm{C}$, the cells were analyzed via flow cytometry using the Cell Lab Quanta ${ }^{\mathrm{TM}}$ SC flow cytometer and associated Cell Lab Quanta SC MPL analysis software version 1.0 (Beckman Coulter, Inc., Brea, CA, USA).

Western blot analysis. Cells were lysed (30 min, on ice) in protein extraction lysis buffer (Intron Biotechnology, Inc., Seongnam, Korea), and centrifuged (12,000 x g, $\left.15 \mathrm{~min}, 4^{\circ} \mathrm{C}\right)$. The resulting supernatant was transferred to a fresh tube, and the concentration of extracted protein was quantified via the BCA protein assay (Pierce; Thermo Fisher Scientific, Inc.), using bovine serum albumin (BSA; Pierce; Thermo Fisher Scientific, Inc.) as a standard. Approximately $10 \mu \mathrm{g}$ of protein from each lysate was solubilized in Laemmli sample buffer, separated by 3-8 or 4-20\% SDS-PAGE. Separated proteins were transferred to a polyvinylidene difluoride nanofiber membrane (Amomedi, Gwangju, Korea). The membranes were blocked for $1 \mathrm{~h}$ at room temperature with $5 \% \mathrm{BSA}$, and incubated overnight at $4^{\circ} \mathrm{C}$ with primary antibodies comprising anti-PI3K, anti-phospho PI3K, anti-Akt, anti-phospho Akt (ser473), anti-caspase-9, anti-caspase-3, anti-PARP, anti-Bax, anti-Bcl-2, anti-cytochrome $c$, and anti- $\beta$-actin (all from Cell Signaling Technology, Danvers, MA, USA). They were then washed three times with TBS-T (0.1\% Tween-20, $50 \mu \mathrm{M}$ Tris- $\mathrm{HCl} \mathrm{pH} 7.5$, and $150 \mu \mathrm{M} \mathrm{NaCl})$, and incubated for $1 \mathrm{~h}$ at room temperature with secondary antibodies, prior to being rewashed a further three times with TBS-T. Protein signals were visualized using the WestSave Up ECL kit (AB Frontier Co., Ltd., Seoul, Korea), and detected using the Microchemi 4.2 device (DNR Bioimaging Systems, Jerusalem, Israel).
Statistical analysis. Experiments were performed in triplicate and expressed as the mean \pm standard deviation (SD). The differences in protein expression between untreated cells and treated cells were analyzed by a one-way analysis of variance followed by Dunnett's t-test w, using GraphPad Prism Software version 6.0 (GraphPad Software Inc., La Jolla, CA, USA). $\mathrm{P}<0.05$ was considered to indicate a statistically significant difference.

\section{Results}

Adenosine suppresses cell growth via the $A_{1}$ and $A_{2 a}$ adenosine receptors in $\mathrm{FaDu}$ cells. To evaluate the effects of adenosine on the viability of FaDu cells, MTT assays was performed in which $\mathrm{FaDu}$ and oral keratinocytes cells were treated with 1-3 mM of adenosine. As presented in Fig. 1A, the growth of NHOKs was unaffected by treatment with adenosine concentrations $<1.5 \mathrm{mM}$, but was inhibited by $8.6 \%$ in response to treatment with $3 \mathrm{mM}$ adenosine, although this change was not statistically significant. By contrast, FaDu cell growth was inhibited in response to treatment with $1.5 \mathrm{mM}$ adenosine, and furthermore, this effect increased dose-dependently until it reached a maximum level at $3 \mathrm{mM}$ adenosine. RT-PCR was used to confirm the presence of adenosine receptors in FaDu cells. The results of PCR revealed that the FaDu cells expressed $A_{1}$ and $A_{2 a}$ adenosine receptor mRNA expression, with the $A_{2 a}$ adenosine receptor mRNA being most strongly expressed of the two adenosine receptors. However, the $\mathrm{A}_{3}$ adenosine receptor was not detected (Fig. 1B). Furthermore, the results of western blot analysis revealed that the $\mathrm{FaDu}$ cells expressed $A_{1}$ and $A_{2 a}$ adenosine receptor proteins, with the expression level of $\mathrm{A}_{2 \mathrm{a}}$ receptor protein being the more strongly expressed of the two genes. The $\mathrm{A}_{3}$ adenosine receptor protein was not detected (Fig. 1C). To evaluate the effects of the adenosine receptors on the growth of adenosine-treated FaDu cells, MTT assays were performed with ATL-444, an $\mathrm{A}_{1}$ and $\mathrm{A}_{2 \mathrm{a}}$ adenosine receptor antagonist. The results of these assays confirmed that inhibition of the growth of adenosine-treated FaDu cells was reversed upon ATL-444 treatment (Fig. 1D). Taken together, these findings indicate that adenosine suppresses the growth of FaDu cells via two types of adenosine receptors.

Adenosine induces apoptosis in FaDu cells. A DNA fragmentation assay was used to ascertain whether the mechanism underlying the adenosine-induced cytotoxic effect on $\mathrm{FaDu}$ cells was associated with apoptosis. DNA ladder formation was observed in cells treated with $3 \mathrm{mM}$ adenosine for $24 \mathrm{~h}$ (Fig. 2A), indicative of the induction of apoptosis. This observed apoptotic cell death was subsequently analyzed and quantified using Hoechst 33342 staining and fluorescence microscopy, respectively. The results of these analyses revealed that whereas the majority of control cells contained intact genomic DNA, adenosine-treated FaDu cells instead exhibited condensed chromatin (Fig. 2B). To study the potential mechanisms by which adenosine induced apoptosis in the FaDu cells, the effect of adenosine on the proportion of apoptotic cells was evaluated by flow cytometry using Annexin V-FITC and PI staining. FaDu cells were treated with $3 \mathrm{mM}$ adenosine for $24 \mathrm{~h}$, and the cell population was then 
A
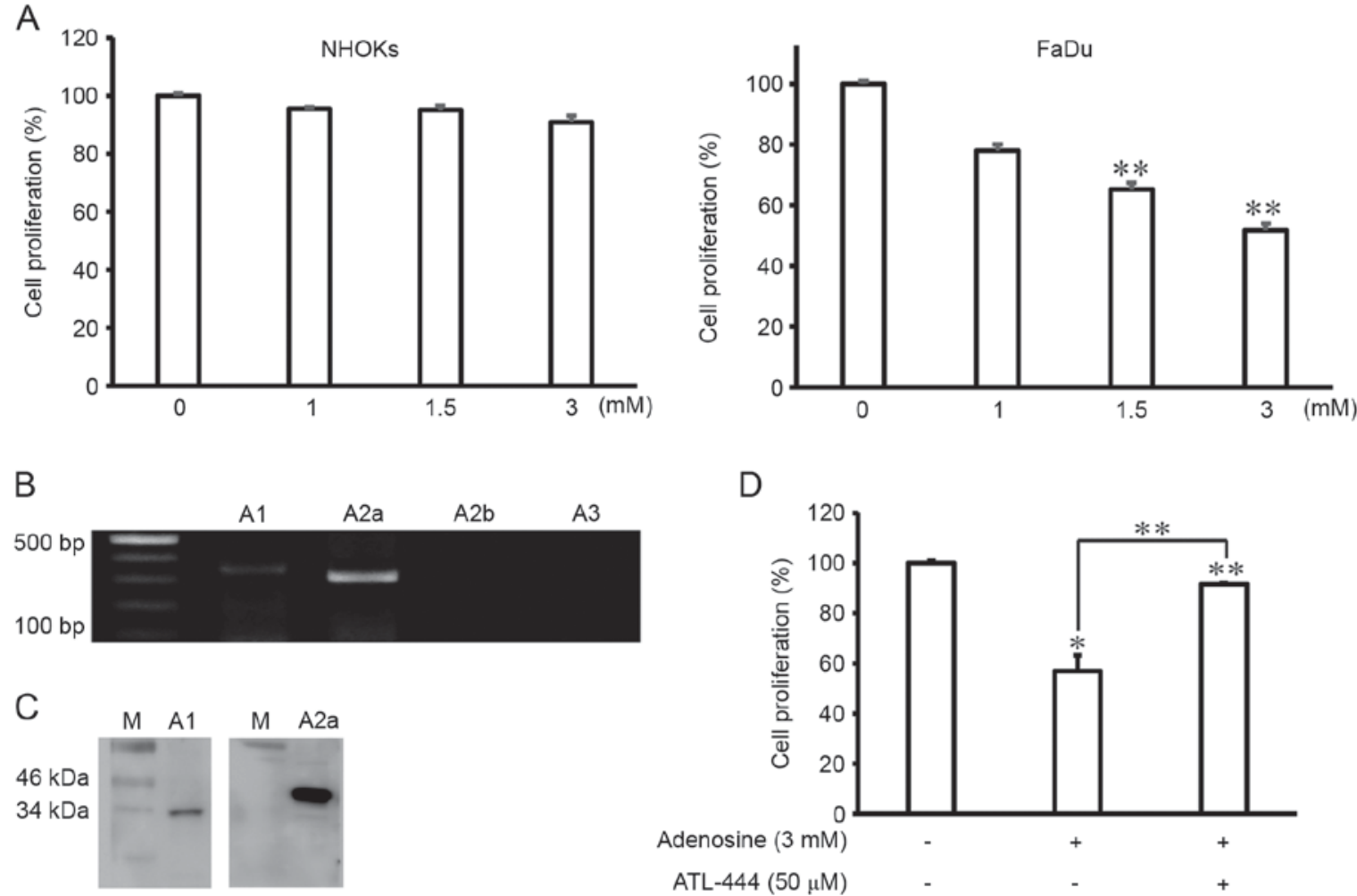

ATL-444 (50 $\mu \mathrm{M})$

Figure 1. Adenosine induces cell death in FaDu cells via the $\mathrm{A}_{1}$, and $\mathrm{A}_{2 \mathrm{a}}$ adenosine receptors. (A) NHOKs and FaDu human hypopharynx squamous carcinoma cells were treated with different doses of adenosine $(0,1,1.5$, or $3 \mathrm{mM})$ for $24 \mathrm{~h}$. The resultant cell viability was analyzed using an MTT assay. The results of three experiments $(n=3)$ are summarized. (B) Polymerase chain reaction products for $A_{1}, A_{2 a}, A_{2 b}$, and $A_{3}$ generated using a cDNA template isolated from total RNA of FaDu cells. (C) $A_{1}$ and $A_{2 a}$ adenosine receptors protein expression confirmed by western blot analysis from FaDu cells. (D) FaDu cells were co-treated with adenosine (3 $\mathrm{mM})$ and ATL-444 (50 $\mu \mathrm{M}$, an adenosine-receptor antagonist) for $24 \mathrm{~h}$. The resulting cell viability was analyzed using an MTT assay. Data represent percentages of cell viability in comparison to control cells that were arbitrarily set to $100 \%$ and are reported as the mean \pm SD of three independent experiments. ${ }^{*} \mathrm{P}<0.05$ and ${ }^{* *} \mathrm{P}<0.01$ vs. untreated group, one-way ANOVA, Dunnett's t-test.

analyzed. As shown in Fig. 2C, the percentage of early and late apoptotic/necrotic adenosine-treated cells increased to 7.3 and $29.1 \%$, respectively.

Adenosine activates cleavage of caspase-3, caspase-9 and PARP via the mitochondrial intrinsic pathway in FaDu cells. To elucidate the mechanisms underlying the effects of adenosine on the early or late induction of apoptosis, western blot analysis was performed to assess the levels of Bax, Bcl-2, and cytochrome $c$ in adenosine-treated cells, since each of these molecules are key to the intrinsic apoptotic pathway. Adenosine treatment of FaDu cells was found to increase and suppress the expression of Bax and Bcl-2, respectively, and to induce the release of cytochrome $c$ from the mitochondria into the cytosol (Fig. 3A). Furthermore, whether adenosine activated caspases was assessed, since these enzymes are critical to the apoptotic signaling cascade. Indeed, adenosine treatment was shown to induce the activation of the cleaved, catalytically active forms of caspase- 3 and -9 in FaDu cells, and furthermore, also promoted the cleavage of PARP, a substrate of activated caspases that mediates apoptotic signaling (Fig. 3B).

Adenosine suppresses PI3K/Akt/mTOR phosphorylation in FaDu cells. The PI3K/Akt signaling pathway regulates cell proliferation and apoptotic signaling in a variety of cancer cells $(16,17)$. Several biological effects of PI3K are mediated via the activation of Akt, a downstream target of PI3K that regulates cell proliferation via the phosphorylation of its own downstream targets, including mTOR. In the present study, adenosine treatment $(3 \mathrm{mM}$ ) of FaDu cells decreased the phosphorylation levels of PI3K, Akt and mTOR (Fig. 4A). Given this result, western blot analysis was performed to evaluate the phosphorylation levels of the downstream mTOR signaling pathway components S6K1, $4 \mathrm{E}-\mathrm{BP} 1$, and eIF4G in response to adenosine treatment. The results of this analysis demonstrated that adenosine-treated $\mathrm{FaDu}$ cells exhibited significantly reduced S6K1, 4E-BP1 and eIF4G phosphorylation levels compared with non-treated cells (Fig. 4B).

\section{Discussion}

Adenosine is critical to various physiological processes and pharmacological actions, including apoptosis, cell proliferation, and differentiation (20). In particular, a number of previously published studies have reported that adenosine inhibits cell growth via diverse biological pathways in a number of cancer cells (21); however, the effect and underlying mechanism of adenosine in head and neck cancer cell lines remains unknown.

Thus, the present study examined the effect of adenosine treatment on cell death in the FaDu human pharyngeal squamous carcinoma cell line. Treatment with $3.0 \mathrm{mM}$ of adenosine was confirmed to significantly decrease the viability of FaDu cells. Next, whether the adenosine $A_{1}, A_{2 a}$, $A_{2 b}$, and/or $A_{3}$ receptors were expressed in the FaDu cells 
A

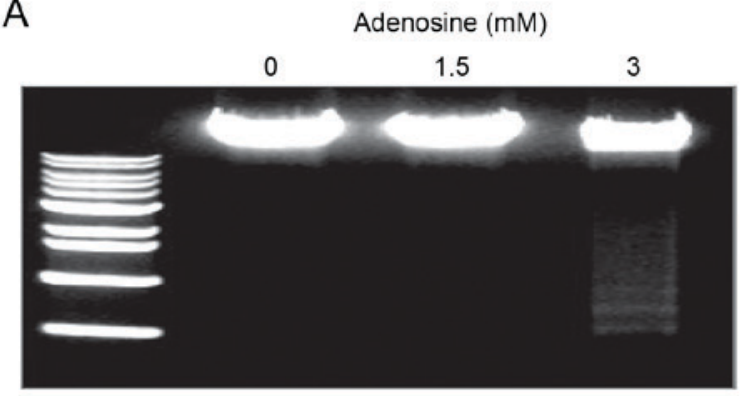

B

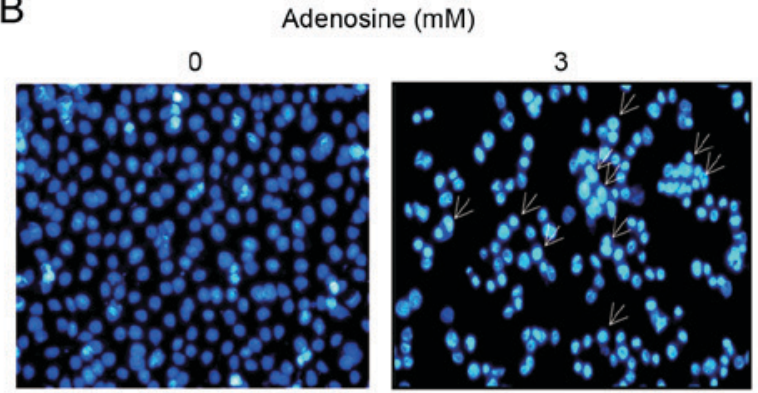

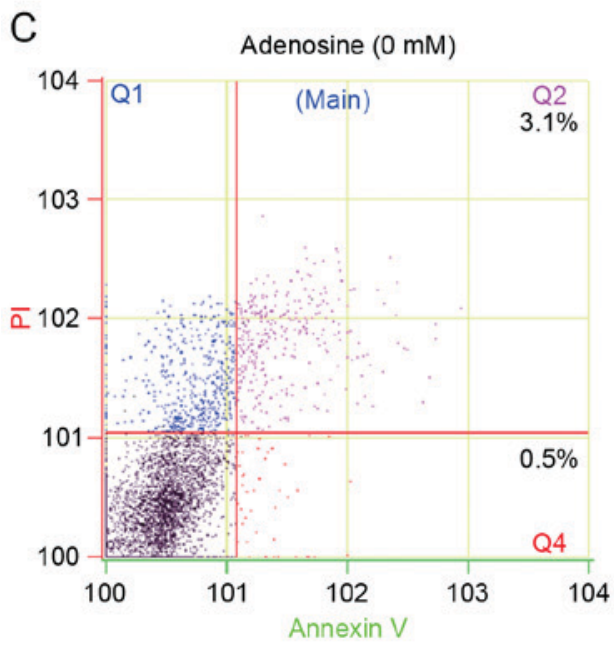

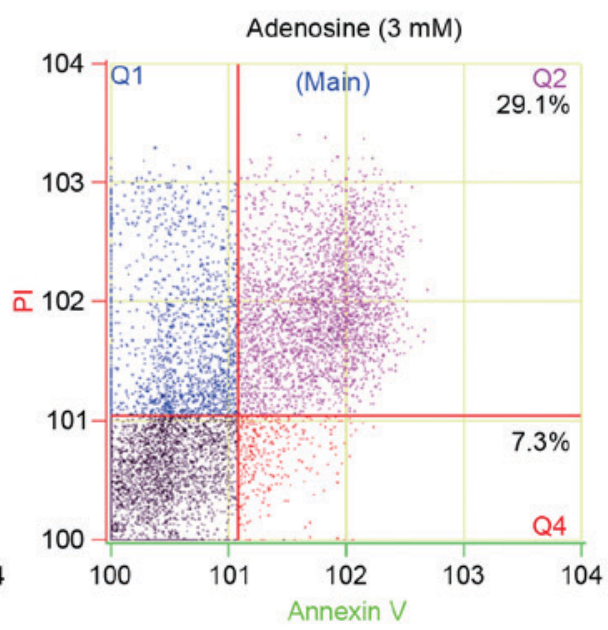

Figure 2. Adenosine induces the apoptosis of FaDu cells. (A) To evaluate genomic DNA fragmentation, FaDu cells were treated with different doses of adenosine $(0,1.5$, and $3 \mathrm{mM})$ for $24 \mathrm{~h}$ before harvesting. Isolated genomic DNA from the cells was then electrophoresed, and visualized using a UV illuminator. (B) Nuclear morphological changes of apoptotic cells following Hoechst staining. Arrows indicate pathologic changes of nucleic condensation. FaDu cells were stimulated with 0 or $3 \mathrm{mM}$ adenosine for $24 \mathrm{~h}$, fixed, stained and observed under a fluorescence microscope (magnification, $\mathrm{x} 100$ ). (C) Cell apoptosis was evaluated by flow cytometric analysis. Following adenosine $(0$ or $3 \mathrm{mM})$ treatment, cells were stained with Annexin V-fluorescein isothiocyanate and PI to visualize apoptotic cell populations. PI, propidium iodide.

was investigated, since these receptors have been previously demonstrated to be highly expressed in a number of different cancer cells (22), and to critically mediate the growth and death of cancerous and normal cells. The expression of the $\mathrm{A}_{1}$ and $\mathrm{A}_{2 \mathrm{a}}$ receptors were confirmed to be expressed in $\mathrm{FaDu}$ cells. Thus, whether adenosine induces cell death via these two receptors in FaDu cells was next investigated, by attempting to rescue adenosine-induced cell-growth inhibition with ATL-444, a known $\mathrm{A}_{1}$ and $\mathrm{A}_{2 \mathrm{a}}$ receptor antagonist. The results of this analysis indicated that the observed adenosine-induced inhibition of FaDu cell viability was receptor-dependent. Furthermore, adenosine-treated FaDu cells were observed to exhibit condensed nuclei and apoptotic morphology. Similarly, adenosine treatment increased the proportion of early apoptotic and late apoptotic/secondary necrotic (Annexin V-positive and PI-negative) cells via the conducted flow cytometric analysis. Given that these results were obtained by observing inter-nucleosomal DNA fragmentation and early or late apoptotic cell populations, we hypothesize that the adenosine-induced FaDu cell growth inhibition is predominantly due to apoptosis.

A number of studies have reported that adenosine induces apoptosis via the activation of caspase- 3 and caspase- 9 , and the subsequent stimulation of mitochondrial reactive oxygen species production in BEL-7404 human liver cancer cells $(23,24)$. Adenosine has also been shown to downregulate expression of the anti-apoptotic factor Bcl-xl, and upregulate the expression of the pro-apoptotic factor $\mathrm{BH} 3$ interacting-domain death agonist via the $\mathrm{A}_{2 \mathrm{a}}$ adenosine receptor, thereby disrupting mitochondrial membrane potentials to facilitate the efflux of cytochrome $c$ from the mitochondria into the cytosol to activate caspase-9 and -3 in human liver cancer HepG2 cells (25). Similarly, adenosine has been reported to induce apoptosis in human colon cancer CW2 and Caco- 2 cells by activating the cleavage of caspase- $9,-3$, and PARP via the $A_{1}$ and $A_{2 a}$ receptors $(26,27)$. Adenosine treatment in the present study increased the protein expression of the pro-apoptotic factor Bax whereas that of the anti-apoptotic factor Bcl-2 was markedly decreased, with the release of cytochrome $c$ into the cytosol was stimulated in FaDu cells. Together, these results confirm that the anticancer effect exerted by adenosine in FaDu cells induces cell death associated via the altered expression of Bax, Bcl-2 and cytochrome $c$.

Currently, therapies targeting the epidermal growth factor receptor, insulin-like growth factor receptor and $\mathrm{PI} 3 \mathrm{~K} / \mathrm{Akt} / \mathrm{mTOR}$ have attracted attention as promising novel treatments for HNSCC patients (28). Of these, inhibition of the $\mathrm{PI} 3 \mathrm{~K} / \mathrm{Akt} / \mathrm{mTOR}$ signaling pathway is predicted to be an extremely effective HNSCC anticancer therapy, since increased PI3K/Akt overexpression is observed in up to $60 \%$ 


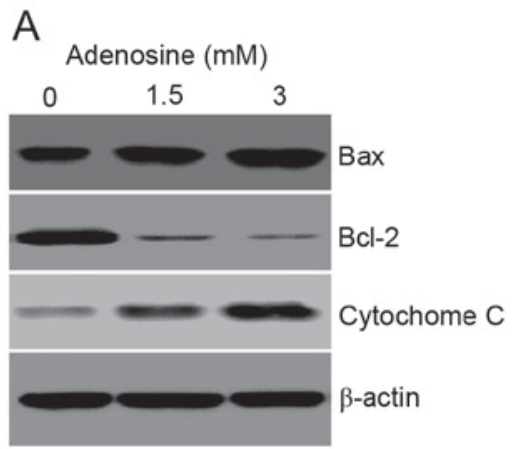

B

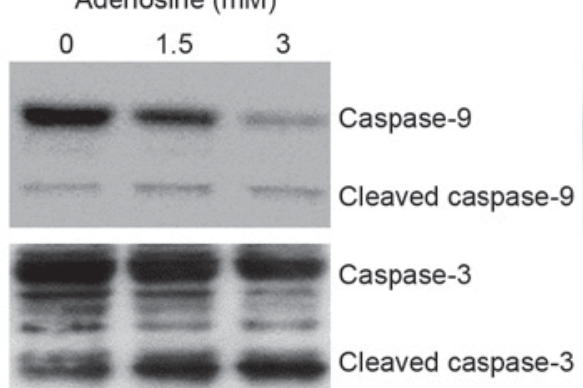

Adenosine (mM)

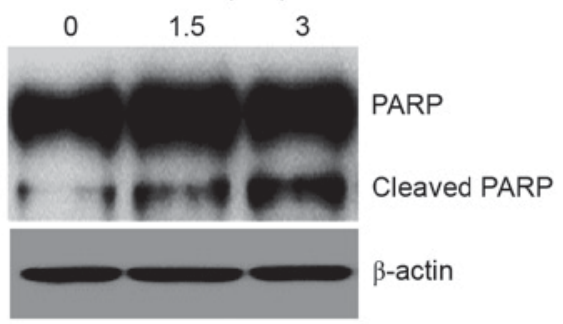

Figure 3. Bax, Bcl-2, and cytochrome $c$ mediate adenosine-induced apoptosis via the mitochondrial intrinsic pathway. FaDu cells were treated with 3 mM adenosine for $24 \mathrm{~h}$, prior to collection of whole cell lysates. Samples were separated using (8-15\%) SDS-PAGE, and resolved by incubation with primary antibodies against (A) Bax, Bcl-2, cytochrome $c$, and (B) caspase-9, caspase-3, and PARP. $\beta$-actin was used as an internal control for the western blot analysis. Data are representative of three experiments that produced similar results. Sample bands ( $\mathrm{n}=3$ ) were densitometrically evaluated. Bcl-2, B-cell lymphoma 2; Bax, Bcl-associated X; PARP, poly(ADP-ribose) polymerase.
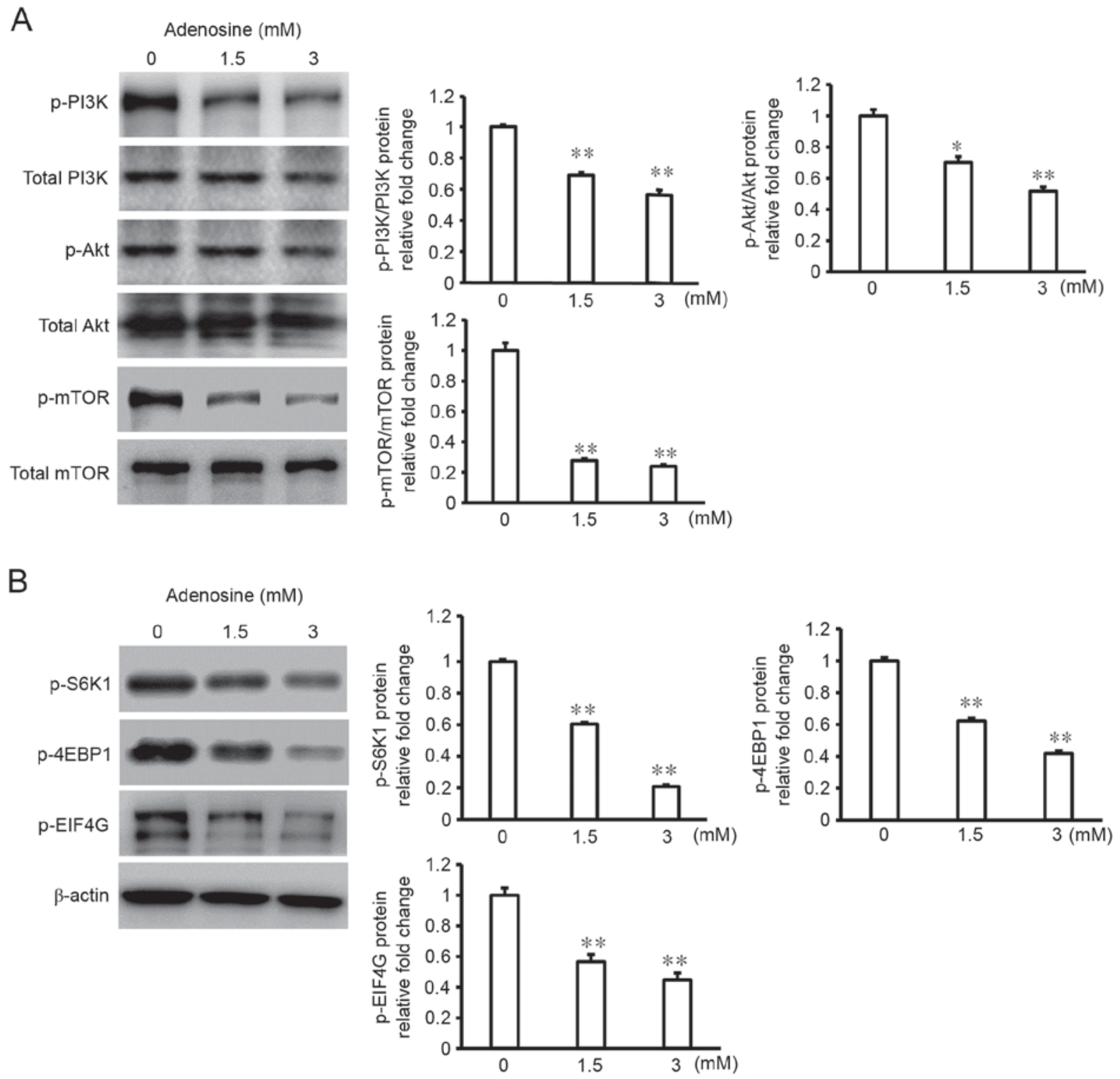

Figure 4. Adenosine treatment of FaDu cells suppresses the PI3K/Akt/mTOR signaling pathway. FaDu cells were treated with $3 \mathrm{mM}$ adenosine for $24 \mathrm{~h}$ prior to collection of whole-cell lysates. Samples were separated using (8-15\%) SDS-PAGE, and resolved by incubation with primary antibodies against (A) phospho-PI3K, total PI3K, phospho-Akt, total Akt, phospho-mTOR, total mTOR, and (B) phospho-S6K1, phospho-4EBP1, and phospho-EIF4 G. $\beta$-actin was used as an internal control for the western blot analysis. Data are representative of three experiments that produced similar results. Sample bands $(\mathrm{n}=3$ ) were densitometrically evaluated. ${ }^{*} \mathrm{P}<0.05$ and ${ }^{* *} \mathrm{P}<0.01$. PI3K, phosphoinositide 3-kinase; Akt, RAC serine/threonine-protein kinase; mTOR, mechanistic target of rapamycin; 4EBP1, eukaryotic translation initiation factor 4E-binding protein 1; EIF4 G, eukaryotic translation initiation factor $4 \gamma 1$. 
of all HNSCC cases $(29,30)$. Akt is a critical downstream target of PI3K and is known to exert numerous biological effects (31), including inhibition of apoptosis via the phosphorylation and inactivation of several targets active in apoptotic pathways (32). Furthermore, mTOR is a downstream target of the Akt and adenosine monophosphate activated protein kinase signaling pathways, as a crucial regulator of cell growth and metabolism in HNSCC (32), and as a component of two similar complexes, mTOR complex 1 and 2 (33). The former of these complexes promotes mRNA translation and protein synthesis via the phosphorylation of S6K1 and 4E-BP1, whereas the latter organizes cytoskeleton function, and regulates Akt phosphorylation (34). To the best of our knowledge, no study has investigated whether adenosine induces apoptosis in oral cancer cells via changes in $\mathrm{PI} 3 \mathrm{~K} / \mathrm{Akt} / \mathrm{mTOR}$ signaling. In the present study, treatment of FaDu cells with $3 \mathrm{mM}$ adenosine resulted in decreased PI3K, Akt and mTOR phosphorylation levels. Furthermore, S6K1, 4E-BP1 and eIF4G phosphorylation levels were investigated, and shown to be significantly reduced in adenosine-treated FaDu cells compared with untreated cells following western blot analyses. Thus, the present study provides novel evidence that adenosine treatment in FaDu cells decreases PI3K, Akt and mTOR phosphorylation levels.

In conclusion, the results of the present study demonstrate that adenosine induced cell death through the mitochondrial intrinsic apoptotic pathway via PI3K/Akt/mTOR signaling pathways in human pharyngeal squamous carcinoma cells. The presented data suggest that adenosine may be a useful chemotherapeutic agent for the treatment of pharyngeal squamous carcinoma.

\section{Acknowledgements}

Not applicable.

\section{Funding}

The present study was supported by research funding from Chosun University (2014).

\section{Availability of data and materials}

All data generated or analyzed during this study are included in this published article.

\section{Authors' contributions}

CSK and SMM conceptualized this experiments. MSC and SMM performed the investigation in the present study. SAL and BRP analyzed the expression of variable proteins by GraphPad Prism Software version of the program 6.0 in this work. JSK analyzed flow cytometry using the Cell Lab Quanta TM SC flow cytometer and associated Cell Lab Quanta SC MPL analysis software version 1.0 in the present study. DKK and YHK interpreted all data. CSK gave final approval of the published article.

\section{Ethics approval and consent to participate}

Not applicable.

\section{Consent for publication}

Not applicable.

\section{Competing interests}

The authors declare that they have no competing interests.

\section{References}

1. Vigneswaran $\mathrm{N}$ and Williams MD: Epidemiological trends in head and neck cancer and aids in diagnosis. Oral Maxillofac Surg Clin North Am 26: 123-141, 2014.

2. Rothenberg SM and Ellisen LW: The molecular pathogenesis of head and neck squamous cell carcinoma. J Clin Invest 122: 1951-1957, 2012.

3. Whang SN, Filippova M and Duerksen-Hughes P: Recent progress in therapeutic treatments and screening strategies for the prevention and treatment of HPV-associated head and neck cancer. Viruses 7: 5040-5065, 2015.

4. Chaturvedi AK, Engels EA, Pfeiffer RM, Hernandez BY, Xiao W, Kim E, Jiang B, Goodman MT, Sibug-Saber M, Cozen W, et al: Human papillomavirus and rising oropharyngeal cancer incidence in the United States. J Clin Oncol 29: 4294-4301, 2011.

5. Argiris A, Karamouzis MV, Raben D and Ferris RL: Head and neck cancer. Lancet 371: 1695-1709, 2008.

6. ZhaoZ,Kapoian T, Shepard M and LianosEA: Adenosine-induced apoptosis in glomerular mesangial cells. Kidney Int 61: 1276-1285, 2002.

7. Saitoh M, Nagai K, Nakagawa K, Yamamura T, Yamamoto $S$ and Nishizaki T: Adenosine induces apoptosis in the human gastric cancer cells via an intrinsic pathway relevant to activation of AMP-activated protein kinase. Biochem Pharmacol 67: 2005-2011, 2004.

8. Panjehpour M and Karami-Tehrani F: Adenosine modulates cell growth in the human breast cancer cells via adenosine receptors. Oncol Res 16: 575-585, 2007.

9. Gessi S, Merighi S, Varani K, Cattabriga E, Benini A, Mirandola P, Leung E, Mac Lennan S, Feo C, Baraldi S and Borea PA: Adenosine receptors in colon carcinoma tissues and colon tumoral cell lines: Focus on the A(3) adenosine subtype. J Cell Physiol 211: 826-836, 2007.

10. Tanaka Y, Yoshihara K, Tsuyuki M and Kamiya T: Apoptosis induced by adenosine in human leukemia HL-60 cells. Exp Cell Res 213: 242-252, 1994.

11. Merighi S, Mirandola P, Milani D, Varani K, Gessi S, Klotz KN, Leung E, Baraldi PG and Borea PA: Adenosine receptors as mediators of both cell proliferation and cell death of cultured human melanoma cells. J Invest Dermatol 119: 923-933, 2002.

12. Luo X, Budihardjo I, Zou H, Slaughter C and Wang X: Bid, a $\mathrm{Bcl} 2$ interacting protein, mediates cytochrome c release from mitochondria in response to activation of cell surface death receptors. Cell 94: 481-490, 1998.

13. Slee EA, Adrain C and Martin SJ: Executioner caspase-3, -6 and -7 perform distinct, non-redundant roles during the demolition phase of apoptosis. J Biol Chem 276: 7320-7326, 2001.

14. Johnstone RW, Ruefli AA and Lowe SW: Apoptosis: A link between cancer genetics and chemotherapy. Cell 108: 153-164, 2002.

15. Stokoe D, Stephens LR, Copeland T, Gaffney PR, Reese CB, Painter GF, Holmes AB, McCormick F and Hawkins PT: Dual role of phosphatidylinositol-3,4,5-trisphosphate in the activation of protein kinase B. Science 277: 567-570, 1997.

16. Bartholomeusz C and Gonzalez-Angulo AM: Targeting the PI3K signaling pathway in cancer therapy. Exp Opin Ther Targets 16: 121-130, 2012.

17. Kandoth C, McLellan MD, Vandin F, Ye K, Niu B, Lu C, Lu C, Xie M, Zhang Q, McMichael JF, et al: Mutational landscape and significance across 12 major cancer types. Nature 502: 333-339, 2013.

18. Moral M and Paramio JM: Akt pathway as a target for therapeutic intervention in HNSCC. Histol Histopathol 23: 1269-1278, 2008.

19. Díaz-Ruiz C, Montaner B and Pérez-Tomás R: Prodigiosin induces cell death and morphological changes indicative of apoptosis in gastric cancer cell line HGT-1. Histol Histopathol 16: 415-421, 2001. 
20. Ohana G, Bar-Yehuda S, Barer F and Fishman P: Differential effect of adenosine on tumor and normal cell growth: Focus on the A3 adenosine receptor. J Cell Physiol 186: 19-23, 2001.

21. Gessi S, Merighi S, Sacchetto V, Simioni C and Borea PA: Adenosine receptors and cancer. Biochim Biophys Acta 1808: 1400-1412, 2011.

22. Fishman P, Bar-Yehuda S, Synowitz M, Powell JD, Klotz KN, Gessi S and Borea PA: Adenosine receptors and cancer. Handb Exp Pharmacol 193: 399-441, 209.

23. Thakur S, Du J, Hourani S, Ledent $\mathrm{C}$ and Li JM: Inactivation of adenosine $\mathrm{A} 2 \mathrm{~A}$ receptor attenuates basal and angiotensin II-induced ROS production by Nox 2 in endothelial Cells. J Biol Chem 285: 40104-40113, 2010.

24. Ma Y, Zhang J, Zhang Q, Chen P, Yu S, Liu H, Liu F, Song C, Yang D and Liu J: Adenosine induces apoptosis in human liver cancer cells through ROS production and mitochondrial dysfunction. Biochem Biophys Res Commun 448: 8-14, 2014.

25. Shirali S, Aghaei M, Shabani M, Fathi M, Sohrabi M and Moeinifard M: Adenosine induces cell cycle arrest and apoptosis via cyclinD1/Cdk4 and Bcl-2/Bax pathways in human ovarian cancer cell line OVCAR-3. Tumour Biol 34: 1085-1095, 2013.

26. Yasuda Y, Saito M, Yamamura T, Yaguchi T and Nishizaki T: Extracellular adenosine induces apoptosis in Caco-2 human colonic cancer cells by activating caspase-9/-3 via A2a adenosine receptors. J Gastroenterol 44: 56-65, 2009.
27. Saito M, Yaguchi T, Yasuda Y, Nakano T and Nishizaki T: Adenosine suppresses CW2 human colonic cancer growth by inducing apoptosis via A1 adenosine receptors. Cancer Let 290: 211-215, 2010.

28. Gao W, Li JZ, Chan JY, Ho WK and Wong TS: mTOR pathway and mTOR inhibitors in head and neck cancer. ISRN Otolaryngol 2012: 953089, 2012.

29. Kundu SK and Nestor M: Targeted therapy in head and neck cancer. Tumour Biol 33: 707-721, 2012.

30. Machiels JP and Schmitz S: New advances in targeted therapies for squamous cell carcinoma of the head and neck. Anticancer Drugs 22: 626-633, 2011.

31. Amornphimoltham P, Sriuranpong V, Patel V, Benavides F, Conti CJ, Sauk J, Sausville EA, Molinolo AA and Gutkind JS: Persistent activation of the Akt pathway in head and neck squamous cell carcinoma: A potential target for UCN-01. Clin Cancer Res 10: 4029-4037, 2004.

32. Merighi S, Mirandola P, Varani K, Gessi S, Leung E, Baraldi PG, Tabrizi MA and Borea PA: A glance at adenosine receptors: Novel target for antitumor therapy. Pharmacol Ther 100: 31-48, 2003.

33. Vanhaesebroeck B and Waterfield MD: Signaling by distinct classes of phosphoinositide 3-kiness. Exp Cell Res 253: 239-254, 1999.

34. Altomare DA and Khaled AR: Homeostasis and the importance for a balance between AKT/mTOR activity and intracellular signaling. Curr Med Chem 19: 3748-3762, 2012. 